\title{
International efforts to measure health expectancy
}

\author{
Margaret R Bone
}

Why measure health expectancy?

Over the past 150 years expectation of life at birth in England and Wales has risen from about 40 to over 70 years. Most of the increase occurred in the first half of this century and was due to the decline in infant mortality and deaths from infectious diseases. Expectation of life at older ages, however, has also increased, but in this case rather over half the rise has taken place since the early $1950 \mathrm{~s}^{1}$ The resulting increase in the proportion of older people in the population will be magnified from about 2020 as people born during the "baby boom" of 1955-70 reach pensionable age. Similar trends are also apparent in other developed countries and have prompted the question of whether extra years of life gained are ones spent in good or poor health. The optimistic argue that the upper limit of the natural human life span is fixed and that declines in mortality are due to decreasing disease incidence so that chronic morbidity is being compressed into an ever shorter period before death. ${ }^{2}$ At the other extreme pessimists expect an expansion of morbidity. They hold that no upper limit to human life is in sight, and that medical intervention, by preserving the lives of the unfit, is resulting in a pandemic of degenerative disease and mental infirmity. ${ }^{34}$ Most starkly put, the question is: "Have the longevity gains increased the number and percentage of very ill, frail people, who require protracted and expensive medical care and whose wellbeing is severely compromised? If so, is the price for more years of life too high for society and also for many individuals?" 5

In between these extreme positions are those who believe that increases in longevity are due both to declines in disease incidence and to the preservation of people in poor health so that an equilibrium between mortality and morbidity is maintained. ${ }^{6}$

To determine which of these scenarios is unfolding requires a measure which combines mortality and morbidity into a single index. Health expectancy is such an index. It is a similar notion to life expectancy but refers to the number of further years of life in good health someone of a specified age can on average expect to enjoy, given prevailing age specific rates of mortality and morbidity. It therefore relates to a hypothetical cohort and is independent of the age structure of the population. Health expectancy is most commonly represented in practice by the more narrowly focused "disability free life expectancy" (DFLE), but the principle can be applied to life free from all or any diseases or their functional consequences. Usually, health expectancy indices have been composed from figures derived from standard life tables in conjunction with evidence from surveys of the prevalence of disability, at successive ages. It is the relationship between health expectancy and life expectancy that is of particular interest.

Health expectancy can be used purely as an indicator, or -in its more developed forms-as an aid to planning policy for health or social security systems.

Origin of the health expectancy measure

The need for a measure of health expectancy together with a method for calculating it were first proposed in the United States in the 1960s. Towards a social report, ${ }^{7}$ published by the US Department of Health Education and Welfare in 1969 , pointed out that both good health and a long life are fundamental objectives of human activity, but that despite the substantial rise in life expectancy in the 20th century it was not known whether the population was in good health. It drew attention in particular to the emergence of chronic degenerative diseases as life expectancy had increased, and recommended the use of indicators, including healthy life expectancy, to monitor the situation. The report also contained the preliminary results of a method of calculating DFLE devised by Sullivan which was fully explicated in $1971 .^{8}$ Sullivan's method remains the most widely used because it both is simple to calculate and can be derived from data which are readily available from life tables and surveys in many developed countries.

Shortly afterwards, in 1973, "the probability of a healthy life through all stages of the life cycle" was stated to be one of a number of "common social concerns" by the OECD. ${ }^{9}$ At about the same time, in 1974, the World Health Organization (WHO) noted the need for indicators of the health status of populations and to determine the priorities and objectives of health systems. ${ }^{10}$ They recommended that person-years in good health should be contrasted with life expectancy years. The need for such an indicator was further supported by a WHO scientific group on the epidemiology of aging in $1984,{ }^{11}$ and the WHO regional office for Europe included DFLE as an optional regional indicator. ${ }^{12}$

DFLE was calculated for several European and North American populations in the 1980 s, but it was collaboration between the Institut National de la Santé et de la Recherche Médicale (INSERM) of France and the Conseil des Affaires Sociales (CAS) of Quebec which led to 
the most sustained international effort to develop robust health expectancy measures-REVES.

\section{The Network on Health Expectancy- REVES}

The international research network for the interpretation of observed values of health expectancy, otherwise known as the Network on Health Expectancy, or REVES (Réseau Espérance de Vie en Santé), was set up in 1989 to harmonise measures of health expectancy, to devise methods for its calculation, and to promote their use. Its first meeting, hosted by CAS of Quebec, was attended by 48 participants from nine countries and from WHO, invited because of its known involvement in research in the field. By the time of its fifth meeting in 1992 there were 70 members of the Network from 19 countries, mainly in western Europe and north America but also in eastern Europe, and from China and Taiwan and three international organisations: OECD and the UN Statistical Office, as well as WHO. The Network is multidisciplinary and participants include demographers, epidemiologists, statisticians, gerontologists, sociologists, and health economists mainly from government and academic institutions. The coordinator of the Network is $\mathrm{J} \mathrm{M}$ Robine of INSERM, France.

The first meeting was devoted mainly to an exchange of papers on recently completed or ongoing work, ${ }^{13}$ and this activity has been a feature of all subsequent meetings. A number of issues emerged from the first, however, and have been the themes of later meetings, working groups, and discussions following presentations of papers.

\section{Health expectancy as an indicator}

One of the objectives of REVES has been to agree on an indicator of health expectancy which can be used to monitor the condition of particular populations over time and to allow comparisons between countries or regions, much as infant mortality is used. In general, the methods devised for calculating the value of the index and the ingenuity of its applications have advanced far beyond the operational definition of the measure of disability on which it is usually based. Research by the US National Center for Health Statistics demonstrates that the prevalence of disability shown by different US studies varies not only with the battery of questions asked, but alsoeven when the questions are very similaraccording to the design and methods of the surveys involved. ${ }^{14}$ Agreement on the definition of disability and the construction of an instrument for measuring it reliably are recognised to be two of the most important steps towards producing an indicator of the kind required. ${ }^{15}$

REVES members early agreed that the principal measure should be disability, as conceptually defined by the International classification of impairments, disabilities, and handicaps (ICIDH). ${ }^{16}$ There are however, many ways of interpreting the concept operationally. One of the most systematic attempts to do so, for the OPCS surveys of disability in Great Britain ${ }^{17}$ which cover physical, mental, sensory, and multiple disabilities in both adults and children ${ }^{18}$ and produce a scale of severity, involves the time consuming collection of extensive information from survey respondents. For the most part, however, those calculating health expectancy are dependent on quite restricted information on disability collected by regular or sporadic population surveys concerned with many other health or general topics. Sometimes the information relates to management of self care, or activities of daily living (ADL), which allow some categorisation of severity of disability among the more disabled section of the population; but in other cases there are data only on whether or not survey informants suffer from a longstanding limiting illness, as in the British general household survey ${ }^{19}$ or the Quebec health survey of $1987 .^{20}$

One concerted effort to produce common measures of disability has been that of the group convened by the WHO Regional Office for Europe and the Netherlands Central Bureau of Statistics to develop common methods and instruments for health interview surveys. ${ }^{21}$ Among other survey questions, it has proposed a series specifically concerned with disability which allows three broad levels of severity to be distinguished. The group, which was established before REVES, includes members who later became attached to the Network.

REVES participants also agreed on a number of other desirable properties of measures of disability or morbidity on which health expectancy indices are based: first they should be applicable to all age groups, including children, so as to allow calculation of health expectancy from birth and young ages; second, they should cover mental disorders, including cognitive decline, and their disabling consequences; and last, the population base for derivation of the measures should include people resident in institutions where a significant proportion of the oldest old and most severely disabled are to be found.

The continuing problem of harmonising operational definitions of disability in developed countries is of minor proportions compared with that of harmonisation between developed and developing countries. Many developing countries are also beginning to experience population aging as premature mortality and birth rates decline, and the UN Statistical Office, under the World Programme for Action Concerning Disabled Persons, has already reviewed methods of collecting data on disability by a number of countries. ${ }^{22}$ They will go on to develop practical guidelines for producing disability statistics from censuses and surveys if requested by the UN Statistical Commission.

\section{The application of the DFLE indicator}

Given the variation in the operational definition of disability, it is remarkable that DFLEs for different developed countries are not very dissimilar. Whereas life expectancy at birth for men in a number of countries (including England and Wales) has in recent years been between just over 70 and 74 years, DFLE has varied between under 60 to $67 .{ }^{23}$ As a proportion of life expectancy, DFLE among men has varied from about $80 \%$ to $90 \%$. Interestingly, although life expectancy is 
generally greater among women than men, DFLE as a proportion of female life expectancy is lower in almost every country.

As remarked earlier, one of the engines of the quest for reliable measures of health expectancy has been the debate about the likely effect of increasing life expectancy on the volume of morbidity in populations. For this reason investigations of change in health expectancy over time and its relationship to change in life expectancy have been among the main objectives of many working in the field. Endeavours are hampered by the same problems of reliability and differences in the instruments used to identify disability as occur when comparing results from different countries at the same period.

Of the comparatively few studies of change within countries over time, some show no clear evidence of trends, whereas others suggest a slightly worsening situation. For example, Bebbington's calculations for England and Wales between 1976 and 1988, which make use of the evidence on the prevalence of limiting longstanding illness from the general household survey, suggest that "recent improvements in health care seemed more to prolong the life of disabled people, than to prevent disablement". ${ }^{24}$ Yet others, who have used information about disability which includes material on degree of severity, have shown similar results but also some evidence that the additional disability is of the less severe kind. Robine concludes from a comparison of time series from several countries that the evolution of life expectancy free of less severe disability at birth (in relation to that of life expectancy) appears to confirm the pessimistic view that an expansion of morbidity is occurring. On the other hand, evidence of the trend in life expectancy free of more severe disability suggests equilibrium (J-M Robine, unpublished data ${ }^{25}$ ). Given the reliability problems which attach to most measures of disability together with the comparative brevity of existing time series, the issue of whether there is an expansion or compression of morbidity or a state of equilibrium between health and life expectancy remains open.

Health expectancy as a policy planning tool A health expectancy indicator of the kind described can be used to watch the way the health of a population is evolving, to show how it compares with that of other populations, and to suggest, once the trend becomes clear, whether a compression or expansion of morbidity is in prospect. It does not of itself suggest any way in which improvement can be hastened or deterioration reversed, nor what the causal influences on such trends might be.

To be of value for the planning of health systems-that is, to indicate the relative benefits of different kinds of interventions and targets for them-the measure of health expectancy has to be applied, and preferably derived and constructed, in a different way. Papers on these developments are among the most exciting and promising to have been brought together at meetings of REVES.

Two studies illustrate the potential of this approach. One by Mathers (C Mathers, 1992; unpublished ${ }^{25}$ ), using Australian cross sectional data on disability and the underlying condition reported by informants, suggests the effects on both life and health expectancies which would result from the total elimination of each of the major disease groups. His calculations indicate that for disease groups which cause significant disability but little mortality (like musculoskeletal conditions) there would be considerable gains in disability free life expectancy and equivalent reductions in expectation of life with disability. For disease groups like circulatory conditions which result in significant mortality and disability there are gains in life expectancy both with and without disability (due to other causes), but the latter substantially outweigh the former.

The Sullivan method of calculating health expectancy based on cross sectional information takes account of any reversals of disability, but does not make this explicit. In fact, studies have shown that many of those who become disabled, even at older ages, regain their functioning within a few years. ${ }^{2627}$ Moreover, because the Sullivan method deals with means, it implies that the probabilities of death are the same for those with and without disability. It is to take account of the essentially dynamic nature of the course of health that the use of longitudinal surveys has grown and is advocated by REVES (M C Myers, unpublished ${ }^{25}$ ). The approach makes it possible to examine and compare the experience of real, rather than hypothetical, cohorts to aid the identification of trends. ${ }^{28}$ Longitudinal data can be used to construct multistate life tables and other forms of event history analysis which allow an individual's movements through various health states to be captured and related to other currents of their experience.

Crimmins and her colleagues (unpublished ${ }^{25}$ ) have used material from the US longitudinal study of aging to simulate future expectation of life with and without disability under variable assumptions. They show that reducing mortality alone increases the prevalence of disability, and that delaying the onset of disease leads to the greatest reduction in prevalence-greater than rehabilitation. They point out, like Mathers, that some of the most common disabling diseases are non-lethal-osteoarthritis and sensory impairments-and concludes that research efforts should concentrate on delaying the onset of these diseases "if we are not to have longer life but worsening health".

Both papers give quantitative form to what may seem to be a common sense view of broad health intervention priorities for the older population. Specific guidance on realistic intervention strategies, however, requires more complex models and more extensive longitudinal information on the dynamics of both morbidity and disability, as well as on risk factors and service use, usually from more than one source. Thus Liu et al, ${ }^{29}$ in dealing with actuarial aspects of health expectancy, combine information from one cross sectional and two longitudinal surveys to draw inferences for private insurance financing of long term care for the elderly. They point out that public policies for long term care can employ the same information. 
A paper by Wolfson and Manton, presented at the fifth meeting of REVES in 1992 (M C Wolfson, K G Manton, unpublished ${ }^{25}$ ), advocated the development of a microsimulation model more complete and integrated than models already in use. With such methods, the authors say: "We could estimate not only conventional measures like cause-deleted life expectancy, but also 'risk-deleted' or 'intervention-added'". They add that the resulting demonstration of the morbidity-and not just the mortalityassociated with various diseases might encourage the reallocation of health resources away from acute end stage intervention towards efforts to reduce or prevent more prevalent but less fatal chronic conditions, together with the associated disabilities.

\section{The value of international cooperation}

An indicator of health expectancy was developed 20 years before the foundation of REVES and applications and publications proliferated in the 1980s. REVES, by providing a forum for the exchange and coalescence of ideas on health expectancy, has had a synergistic effect. It has generated research which might otherwise not have been undertaken and disseminated understanding of the complexities of the issues involved. Perhaps of most importance, REVES has obliged the growing number of researchers in the field to confront the problems of producing a reliable indicator, and to give greater thought to the uses of health expectancy to policy planners.

1 Office of Population Censuses and Surveys. Mortality statistics, general, England and Wales. OPCS Series DH1, No 24, table 14) London: OPCS, 1992.

2 Fries JF. Aging, natural death, and the compression of morbidity. $N$ Engl $\mathcal{f}$ Med 1980; 303: 130-5.

3 Kramer M. The rising pandemic of mental disorders and associated diseases and disabilities. Acta Psychiatr Scand 1980; 62 (suppl 285): 282-97.

4 Gruenberg EM. The failures of success. Milbank $Q 1977$; 55: 3-24.

5 Verbrugge LM. Recent, present, and future health of American adults. Annu Rev Public Health 1989; 10: 333-61.

6 Manton KG. Changing concepts of morbidity and mortality in the elderly population. Milbank $Q 1982 ; 60$ : 183-244.
7 US Department of Health, Education and Welfare. Towards a social report. Washington DC: US Government Printing Office, 1969.

8 Sullivan DF. A single index of mortality and morbidity. HSMHA Health Rep 1971; 86: 347-54.

9 OECD. List of social concerns common to most OECD countries. Paris: OECD, 1973.

10 World Health Organization. Modern management methods and the organization of health services. Public Health Papers 1974: 55.

11 World Health Organization. The uses of epidemiology in the study of the elderly: reports of a WHO scientific group on the study of the elderly: reports of a WHO scientific group on the
epidemiology of aging. Geneva: World Health Organization,
1984 (Technical Report Series No 706).

12 World Health Organization. Targets for health for all. In: Targets in support of the European regional strategy for health for all. Copenhagen: WHO, 1985.

13 Robine J-M, Blanchet M, David JE, eds. Health expectancy. (OPCS series SMPS, No 54). London: HMSO, 1992.

14 US Department of Health and Human Services. Measuring the activities of daily living among the elderly: a guide to national surveys. (Interagency Forum on Aging.) Washington DC: US Government Printing Office, 1989.

15 Robine J-M. Disability free life expectancy. In: Robine J-M, Blanchet M, Dowd JE, eds. Health expectancy. London:
HMSO, 1992.

World Health Organization. Classification of impair
disabilities and handicaps. Geneva: WHO, 1980.

disabilities and handicaps. Geneva: WHO, 1980 .
17 Martin J, Meltzer H, Elliot D. The prevalence of disability Martin J, Meltzer H, Elliot D. The prevalence of disability
among adults-OPCS surveys of disability in Great Britain. among adults-OPCS surveys of disabili
(Report 1.) London: HMSO, 1988.

18 Bone $\mathrm{M}$, Meltzer $\mathrm{H}$. The prevalence of disability among children-OPCS surveys of disability in Great Britain. (Report 3.) London: HMSO, 1989.

19 Office of Population Censuses and Surveys. The general household survey 1990. London: HMSO, 1992.

20 Wilkins R. Health expectancy in Quebec, 1987. In: Robine $\mathrm{J}-\mathrm{M}$, Blanchet $\mathrm{M}$, Dowd $\mathrm{JE}$, eds. Health expectancy. London: HMSO, 1992.

21 World Health Organization. Netherlands Central Bureau of Statistics. Consultation to develop common methods and instruments for health interview surveys. Voorburg: Netherlands Central Bureau of Statistics, 1990.

22 United Nations. Disability statistics compendium. Statistics on Special Population Groups, series Y, No 4. New York: United Nations, 1990.

23 REVES. Health expectancy statistical world yearbook. Institut National de la Santé et de la Recherche Médicale -National Institutes of Health, 1991.

24 Bebbington AC. The expectation of life without disability in England and Wales 1976-88. Popul Trends 1991, Winter:

25 Available from REVES Network Coordinator pending publication; contact Dr M R Bone for details.

publication; contact Dr M R Bone for details.
C. disabilities in older men. $\mathcal{f}$ Gerontol 1985; 40: 426-33.

27 Manton KG. The dynamics of population aging: demography and policy analysis. Milbank $Q$ 1991; 69 : 309-38.

28 Bone $M$. A multi-cohort longitudinal study. In: Robine $\mathrm{J}-\mathrm{M}$, Blanchet $\mathrm{M}$, Dowd JE, eds. Health expectancy London: HMSO, 1992.

29 Liu K, Manton KG, Liu BM. Morbidity, disability and long term care for the elderly: implication for insurance financing. Milbank $Q$ 1990; 68: 445-92. 